\title{
A pandemia Covid-19: crise e deterioração do mercado de trabalho no Brasil
}

\author{
MARIA APARECIDA BRIDI ${ }^{I}$
}

\section{Introdução}

A LÉM DAS consequências para os sistemas de saúde do mundo, das mudanças na dinâmica econômica, da alteração quanto à circulação de pessoas nos âmbitos local, nacional e internacional, a pandemia causada pelo Sars-CoV-2, popularmente conhecida como Covid-19, provocou, sem dúvida, transformações gigantescas no mundo do trabalho. Atingiu toda a classe trabalhadora de formas diferenciadas: desemprego para uma grande parcela da população durante a pandemia, sobretudo naqueles segmentos econômicos que demandam tanto a presença física do trabalhador quanto a presença física dos clientes/usuários; efeitos imediatos no setor de serviços, tais como o turismo e toda a sua cadeia produtiva, hotelaria, aviação, restaurantes; a chamada "economia criativa", shows, eventos, feiras, cinema, entre outros. Para outros segmentos, significou a intensificação do trabalho para quem continuou a trabalhar, caso de entregadores via plataformas digitais, profissionais de saúde, os trabalhadores remotos (teletrabalhadores), aqueles que tiveram que migrar suas atividades para o ambiente doméstico, caso dos professores da educação básica à pós-graduação, cujas atividades profissionais passaram a ser realizadas a distância (virtualmente); os trabalhadores informais; os trabalhadores figurados como “empreendedores", cuja condição de desproteção desnudou sua condição de vulnerabilidade. Para os trabalhadores que permaneceram trabalhando, nas chamadas atividades essenciais, sistema financeiro, supermercado, farmácia, entre outros, o risco da contaminação e de adoecimento.

Os diferentes impactos no trabalho e as condições de sua realização no contexto da crise sanitária decorrente da Covid-19 tendem, assim, a se constituir em um novo marco temporal que passa a balizar os estudos do trabalho, tal como o foi a reforma trabalhista ocorrida no Brasil em 2017, que impôs aos estudiosos do trabalho a necessidade de analisar temporalmente, a olhar para o antes e o depois. Sem essa mirada histórica e da conjuntura que a antecede, o conhecimento produzido, embora importante, se constitui apenas em um instantâneo fotográfico. Portanto, para uma análise do que acontece com o mercado de trabalho no contexto da pandemia, é necessário retomarmos o contexto que a antecedeu. A crise sanitária como acontecimento mais vísivel e 
concreto constitui-se em ponto de partida para compreender o que acontece com o trabalho no Brasil.

No Brasil, essa crise sanitária chegou em um momento de grave crise econômica, acirrada pelos conflitos político desde a reeleição de Dilma Rousseff em 2014, seu impeachment em 2016, e os desdobramentos que resultaram em recessão, desemprego e alterações profundas na regulação pública do trabalho. A reforma trabalhista, de 2017, por exemplo, teve um papel importante na legalização de um conjunto de práticas no mercado de trabalho que antes seriam consideradas ilegais ou fraudulentas (Krein et al., 2018), além de favorecer a negociação individual, a redução do poder de negociação dos sindicatos e o aprofundamento da frágil estruturação do mercado de trabalho, que é histórica, no país.

A partir da análise de dados do IBGE sobre o mercado de trabalho no período pré e durante pandemia, além de literatura pertinente, este artigo contempla três dimensões: (i) um breve panorama sobre o contexto de crise econômica e do emprego e das mudanças que redundaram na reforma laboral de 2017, os indicadores do mercado de trabalho no período que antecedem a crise sanitária; (ii) os indicadores do mercado de trabalho no contexto da pandemia, que sinalizam os seus reflexos sobre o trabalho; (iii) os desafios impostos pela intensificação da agenda neoliberal dos últimos quatro anos.

A crise sanitária potencializou a fragilidade do mercado de trabalho que vinha em franco processo de deterioração nos últimos quatro anos. Atingiu, contudo, e de forma contundente e de diversas maneiras a classe trabalhadora, os níveis de ocupação/desocupação, a informalidade, dos empregados dos setores público e privado aos informais, como veremos no artigo. ${ }^{1}$

\section{Os antecedentes econômicos \\ e políticos da crise sanitária no Brasil}

Do ponto de vista do mercado de trabalho, a dinâmica econômica, a criação de empregos formais e a melhoria dos indicadores sociais durante os governos de Luiz Inácio Lula da Silva (2003-2010) e Dilma Rousseff (2011-2015) deveram-se a uma confluência de fatores, como a economia internacional favorável às commodities, mas também do ponto de vista interno, das políticas neodesenvolvimentistas caracterizadas pela indução positiva da economia pelo Estado, acompanhada das políticas sociais distributivas, que ampliaram o poder de compra da população brasileira. Diversos estudiosos corroboram com essa visão da economia do trabalho (Pochmann, 2011; Krein; Véras de Oliveira, 2019; Araújo; Véras de Oliveira, 2014; Bresser-Pereira; Theuer, 2012), entre outros. O boom econômico, portanto, decorrente da política de Estado, repercutiu positivamente no mercado de trabalho, visto ter levado o país ao menor patamar de desemprego da história, com taxas em torno dos $6 \%$ de acordo com dados da PNAD-IBGE para o ano de 2013, por exemplo. Esse ciclo foi quebrado com as crises econômica e política de 2015 e amplificada desde então. 
Os resultados positivos do mercado de trabalho se deviam, entre outros, ao Programa de Aceleramento do Crescimento (PAC), o PAC I, que contou com investimentos públicos de R\$ 503 bilhões, e o PAC II, com investimentos previstos de R\$ 955 bilhões, destinados a obras de infraestrutura, habitação, rodovias, hidrovias, portos, aeroportos, entre outros. No período, a construção de obras de infraestrutura e um conjunto de ações resultaram em mudanças no mercado de trabalho importantes.

Tomando como exemplo o setor econômico da construção por se tratar de um dos maiores empregadores do país, a construção recebeu investimentos federais de mais de R 400 bilhões, o que favoreceu a evolução do número de empresas ativas e formais. De acordo com os dados do IBGE, da Pesquisa Anual da Indústria da Construção, o número de empresas ativas saltou de 52.870 (ano de 2007) para 131.318 em 2015. Esse crescimento é interrompido com a crise econômica e política caindo para 126.943 mil (2016) e dois anos depois, em 2018, declinou ainda mais, para 124.522 .

Os dados do Ministério do Trabalho e Emprego extraídos da RAIS, portanto outra base de dados, indicam que o setor empregava 1.094 .528 (um milhão, noventa e quatro mil e quinhentos e vinte e oito) trabalhadores em $2000 \mathrm{e}$ que em 2013 esse número alcançou 3.094.153 (três milhões, noventa e quatro mil e cento e cinquenta e três) trabalhadores segundo Gomes (2017). Além da criação de empregos, a conjuntura era de crescente formalização do vínculo, visto que, por exemplo, as obras públicas dependiam da contratação formal dos empregados.

Segundo Filgueiras (2019), em razão das políticas adotadas e da dinâmica da economia mundial favorável, no período entre 2003 e 2014 foram criados mais de 21 milhões de novos postos de trabalho formal. Os dados da PNAD Contínua até 2014 confirmam o incremento da ocupação, da formalização, a redução da desocupação, tendo no período observado, a menor taxa na série histórica, além de crescimento dos ganhos salariais. Os indicadores das taxas de desocupação demonstram a degradação do mercado do trabalho após 2016, como se pode observar na Tabela 1, que informa em termos percentuais o significativo avanço do desemprego a partir do quarto trimestre de 2015.

É a partir de 2016, ano que conjugou a crise política e econômica que os dados do desemprego se ampliam para o patamar de dois dígitos. Esse dado da desocupação, contudo, segundo a literatura, deve ser lido a partir também das informações sobre a subutilização, subocupação, que se refere aos trabalhadores que trabalharam uma quantidade de horas insuficientes. Essas taxas, conforme a PNAD, a partir de 2016 sobem para mais de 20\% em todos os anos analisados.

A subutilização em 2019 e nos primeiro e segundo trimestres de 2020, se comparados a 2014, quase dobrou, por exemplo (chegando a $29,1 \%$ no segundo trimestre de 2020). 
Tabela 1 - Taxas de desocupação nos trimestres selecionados no período 2012$2019(\mathrm{em} \%)$

\begin{tabular}{c|c|c|c|c|c|c|c|c|c}
\hline Trimestre & $\mathbf{2 0 1 2}$ & $\mathbf{2 0 1 3}$ & $\mathbf{2 0 1 4}$ & $\mathbf{2 0 1 5}$ & $\mathbf{2 0 1 6}$ & $\mathbf{2 0 1 7}$ & $\mathbf{2 0 1 8}$ & $\mathbf{2 0 1 9}$ & $\mathbf{2 0 2 0}$ \\
\hline $\mathbf{1}^{\circ}$ trimestre & 7,9 & 8,0 & 7,2 & 7,9 & 10,9 & 13,7 & 13,1 & 12,7 & 12.1 \\
\hline $\mathbf{4}^{\circ}$ trimestre & 6,9 & 6,2 & 6,5 & 8,9 & 12,0 & 11,8 & 11,6 & 11,0 & $\mathbf{1 3 . 3}^{\boldsymbol{*}}$ \\
\hline
\end{tabular}

Fonte: IBGE-Pesquisa Nacional por Amostra de Domicílio Contínua. ${ }^{2}$ Elaboração própria.

* Segundo semestre de 2020.

Tabela 2 - Taxa composta de subutilização da força de trabalho das pessoas de 14 anos ou mais de idade (em \%)

\begin{tabular}{l|c|c|c|c|c|c|c|c|c}
\hline Trimestre & $\mathbf{2 0 1 2}$ & $\mathbf{2 0 1 3}$ & $\mathbf{2 0 1 4}$ & $\mathbf{2 0 1 5}$ & $\mathbf{2 0 1 6}$ & $\mathbf{2 0 1 7}$ & $\mathbf{2 0 1 8}$ & $\mathbf{2 0 1 9}$ & $\begin{array}{c}\mathbf{2 0 2 0} \\
\left(1^{\circ} \mathrm{e} 2^{\circ} \text { trimestres }\right)\end{array}$ \\
\hline $\mathbf{1}^{\circ}$ trimestre & 20,9 & 17,9 & 15,5 & 16,5 & 19,3 & 24,0 & 24,6 & 25,0 & 24,4 \\
\hline $\mathbf{4}^{\circ}$ trimestre & 16,7 & 14,9 & 14,9 & 17,3 & 22,2 & 23,5 & 23,8 & 23,0 & $29,1 \%^{*}$ \\
\hline
\end{tabular}

Fonte: IBGE. Elaboração própria.

Nota 1: Taxa composta de subutilização da força de trabalho corresponde aos subocupados por insuficiência de horas + desocupados + força de trabalho potencial.

* Segundo trimestre de 2020.

Esse cenário do mercado de trabalho cujos indicadores sinalizam para a degradação nos últimos anos é um processo vinculado aos problemas econômicos decorrentes de uma nova dinâmica instaurada após 2016 com o governo de Michel Temer. Nesse cenário, as forças neoliberais adquiriram novo ímpeto articuladas com o governo resultando numa escalada de contrarreformas com o objetivo de flexibilização ainda maior do trabalho, dos sistemas de proteção da exploração do trabalhador.

Em novembro de 2017 a classe trabalhadora brasileira sofreu um dos mais duros golpes contra os direitos do trabalho estabelecidos pela Consolidação das Leis Trabalhistas (CLT). A reforma trabalhista, ou, em outros termos, a contrarreforma, que se sucedeu sob o governo de Michel Temer (2016), vem na esteira de um fenômeno mundial (Lúcio, 2018), no qual o capital financeiro assumiu uma agenda de retroação de sistemas protetivos do trabalho com vistas a retomar de forma plena o controle sobre o trabalho. As reformas pós-2017 vêm na esteira da ordem mundial implantada desde os anos 1990 no Brasil, ${ }^{3}$ que adotou a bandeira da flexibilização de contratos de trabalho, da desregulamentação laboral e da responsabilização individual pelo desemprego.

No caso do Brasil, entre os argumentos justificadores da contrarreforma trabalhista - em comum nos anos 1990 e 2017 - estava a tese da "modernização" da legislação com vistas a adequar a lei às "novas" configurações do trabalho 
e dos mercados de trabalho flexíveis e desregulados. A tese da criação de empregos e de melhoria da qualidade do trabalho também foi fartamente utilizada pelos agentes do mercado, das mídias e por políticos conservadores. Todavia, os estudos que vêm monitorando os seus efeitos demonstram abundantemente as promessas não cumpridas. ${ }^{4}$

No período que se seguiu ao impeachment de Dilma Rousseff (2016), emergiu com força total a sanha do desmonte dos sistemas de proteção do trabalho. Em nome de uma suposta austeridade, Temer aprovou a Emenda 95, a Emenda do Teto dos Gastos, impondo um limite por vinte anos no país, gerando efeitos sobre a geração de emprego e da renda, com a paralisação das obras públicas e de programas que favoreciam a criação de empregos e sua formalização.

Sob o argumento da criação de empregos, da melhoria da qualidade do emprego e da "modernização" do trabalho, foram aprovadas: a Lei da Terceirização (n.13.429/2017) e, em novembro de 2017, a Lei da Reforma Trabalhista (n.13.467 /2017), que representou um dos maiores retrocessos do sistema de proteção do trabalho. A contrarreforma do trabalho que alterou cerca de 200 artigos da CLT legalizou um conjunto de práticas de contratação de trabalho antes consideradas ilegais, fraudulentas (Krein; Véras de Oliveira, 2019). Dispôs para o mercado inúmeras possibilidades de formas de contratação flexíveis e novas modalidade contratuais. Essas modalidades emergentes, para Portella (2020), se deram com a introdução do contrato de trabalho intermitente, que consiste na prestação de serviços de forma não contínua, alternando dias, meses e/ou por algumas horas; na terceirização ampla e irrestrita, na medida em que estende para todas as atividades da empresa; e a figura do trabalhador autônomo exclusivo que, paradoxalmente, passou a permitir a contratação de trabalhadores autônomos de forma exclusiva e contínua, condições vedadas pela CLT antes da reforma. Tratou-se de um processo rápido, com pouquíssimos debates junto aos atores envolvidos. $\mathrm{O}$ balanço da reforma feito por inúmeros pesquisadores do trabalho no país, com destaque para a Rede de Estudos e Monitoramento Interdisciplinar da Reforma Trabalhista (Remir), demonstra que os resultados da reforma não apenas não criaram empregos, como contribuíram para a precarização do mercado de trabalho. A reforma "não cumpriu com a promessa de expansão do emprego e tampouco com a formalização do trabalho, visto que "as taxas de desemprego têm sofrido poucas alterações (tanto o desemprego aberto quanto a subutilização da força de trabalho)" que, segundo Filgueiras $(2019$, p.36),

$\mathrm{O}$ desemprego aberto no trimestre imediatamente anterior à vigência da reforma, terminado em outubro de 2017 , atingia 12,740 milhões de pessoas, ou $12,2 \%$ da população economicamente ativa, contra 12,984 milhões $(12,3 \%)$ no trimestre encerrado em maio de 2019 . O desemprego total em outubro de 2017 contemplava 26,554 milhões de pessoas $(23,8 \%)$, contra 28,524 milhões em maio (25\%), recorde da série histórica da PNAD. 
Os dados do emprego, as taxas de desocupação e subutilização da mão de obra no país e o crescimento da informalidade demonstram a deterioração do mercado de trabalho, fato evidenciado amplamente pelas pesquisas. ${ }^{5}$

Como o saldo do emprego formal após a reforma é pífio, a participação do trabalho parcial e intermitente nesse resultado alcança $26,7 \%$ até maio de 2019. Contudo, as vagas formais mantidas com tais contratos são ínfimas face à variação de arranjos semelhantes na informalidade. Enquanto empregos formais com contratos intermitentes e parciais cresceram 108.583 entre a implementação da reforma de maio de 2019, a PNAD informa que, entre outubro 2017 e maio 2019 surgiram 951 mil novos subocupados, trabalhando menos do que 40 horas semanais. Eles seriam o público típico para a formalização por meio das novas modalidades de contrato. (Filgueira, 2019, p.38)

Além das taxas de desocupação, outros indicadores da degradação do mercado de trabalho consistem no aumento de trabalhadores informais, sem registro em carteira, mas também o crescimento de trabalhadores por conta própria e formas de trabalho ilegal, como demonstram Krein e Véras de Oliveira (2019, p.109-10):

A soma dos sem registros em carteira, dos autônomos e dos empregadores sem CNPJ é bastante expressiva, abrangendo aproximadamente 40 milhões de ocupados em maio de 2019, incluindo os trabalhadores do setor privado sem carteira (11,4 milhões), os domésticos sem carteira $(4,49$ milhões), os trabalhadores do setor público sem carteira (2,47 milhões), os por conta-própria sem CNPJ (19,09 milhões) e os empregadores sem registro (quase 1 milhão). Neste caso, a denominação mais apropriada não é informalidade, mas ilegalidade, pois se trata de ocupados que, por diferentes razões, estão exercendo atividade profissional fora do marco legal existente no Brasil.

Ao contrário do alardeado pelos seus defensores, essa "reforma" colocou os trabalhadores à mercê da demanda dos empregadores, ampliando ainda mais o poder das empresas. A escalada da reforma laboral e a radicalização e avanço dos desmontes do trabalho é asseverada com a ascensão ao governo por Jair Bolsonaro em 2018. Com uma agenda ultraneoliberal, amplia as reformas pró-mercado articuladas por agentes econômicos e políticos e amplo aval midiático tradicional. A partir do discurso da "austeridade", extinguiu o Ministério do Trabalho e Emprego (MTE), cujas competências originais foram migradas para o Ministério da Economia, da Justiça e Segurança Pública, da Cidadania e da Secretaria de Governo da Presidência da República (Bridi, 2020). Além do significado simbólico denotando insignificância de uma das pastas historicamente mais importantes para a classe trabalhadora, também fragiliza a produção de dados e sistematização das informações sobre o trabalho no país e uma pauta que enfraquece paulatinamente a articulação de políticas públicas de trabalho e renda. 
As alterações do direito do e ao trabalho se estendeu no governo de Jair Bolsonaro também em direção ao desmonte da organização sindical com a edição da Medida Provisória n.873/2019, reforçando o caráter restritivo da Lei n.13.467/2017. Essa MP, que tinha como finalidade asfixiar a organização sindical, condicionava o pagamento das contribuições sindicais além de autorização individual e por escrito pelo empregado, o pagamento via boleto bancário. ${ }^{6} \mathrm{Tal}$ medida, embora não tenha se mantido, merece o registro, dada a tentativa de um golpe fatal no sindicalismo, que precisou agir defensivamente.

No mesmo ano ocorreu a edição da Medida Provisória da "liberdade econômica" de abril de 2019 e aprovada em agosto de 2019, a MP n.881/2019,7 que visou amplificar a flexibilização do trabalho acentuando a exploração dos trabalhadores. Entre os pontos de destaque dessa MP está a liberação das empresas com até 20 empregados do livro de registro de ponto, fragilizando ainda mais o controle sobre a jornada de trabalho. Soma-se a isso a reforma previdenciária de 2020 que, segundo os especialistas na área, atinge todos os trabalhadores dos setores público e privado, mas de forma ainda mais contundente os pobres, dada a dificuldade que impôs para conseguirem aposentadoria. Ao retardar a aposentadoria, arrochar benefícios, segundo Krein (2018), essa reforma aumentou o contingente de trabalhadores excluídos do sistema.

A partir desse breve contexto, argumentamos que a crise e a deterioração do mercado de trabalho brasileiro antecedem a pandemia da Covid-19, mas se aprofundam exponencialmente e, como um fato social total, produzem-se repercussões em todas as direções. Como analisam Teixeira e Borsari (2020, s.p.), os dados do mercado de trabalho de 2020, até o mês de abril, "mostram uma queda expressiva em todas as direções, no contexto da pandemia de Covid-19. O Produto Interno Bruto caiu 1,5\% no primeiro trimestre do ano, em comparação com o trimestre anterior"; refletem, segundo os autores, o movimento de "desaceleração da economia em curso e, principalmente, os efeitos da crise sanitária". Entretanto, essa desaceleração da economia que já estava prevista pelo Banco Central , "afasta a hipótese de que os resultados são efeitos unicamente da crise mais recente" (Teixeira; Borsari, 2020, s.d.), ${ }^{8}$ hipótese que consideramos neste artigo. Vejamos na sequência o que acontece com o trabalho na pandemia.

\section{O mercado de trabalho no contexto da pandemia Covid-19: escancara as desigualdades}

A pandemia da Covid-19 afetou de forma imediata toda a classe trabalhadora do mundo. No caso brasileiro, o mercado de trabalho, durante a crise sanitária, teve uma agudização da piora generalizada das condições, como expressam os dados da Pesquisa Nacional de Amostra por Domicílio (PNAD) realizada pelo IBGE.

A composição da força de trabalho no Brasil em 2020, se comparada ao segundo trimestre de 2019, teve alteração importante, como pode ser visualizado na Tabela 3. Os dados relativos ao segundo trimestre de 2019 revelam uma 
redução da força de trabalho em cerca de dez milhões de pessoas e o consequente aumento da população fora do mercado de trabalho em pouco mais de treze milhões de pessoas.

Tabela 3 - Pessoas por condição em relação à força de trabalho e condição na ocupação - Brasil ${ }^{9}$

\begin{tabular}{l|c|c|c|c|c|c|c}
\cline { 2 - 8 } & \multicolumn{3}{c}{ Estimativas dos trimestres (mil) } & \multicolumn{2}{c|}{$\begin{array}{r}\text { Variação em relação } \\
\text { ao tri 2020.1 }\end{array}$} & \multicolumn{2}{c}{$\begin{array}{c}\text { Variação em relação } \\
\text { ao tri 2019.2 }\end{array}$} \\
\cline { 2 - 8 } & 2019.2 & 2020.1 & 2020.2 & Diferença & VAR\% & Diferença & VAR\% \\
\hline Total & 170864 & 172354 & 173918 & 1565 & 0,9 & 3054 & 1,8 \\
\hline $\begin{array}{l}\text { Na força } \\
\text { de trabalho }\end{array}$ & 106108 & 105073 & 96138 & -8935 & $-8,5$ & -9970 & $-9,4$ \\
\hline $\begin{array}{l}\text { Ocupada } \\
\text { Desocupada }\end{array}$ & 1276342 & 92223 & 83347 & -8876 & $-9,6$ & -9995 & $-10,7$ \\
\hline $\begin{array}{l}\text { Fora da força } \\
\text { de trabalho }\end{array}$ & 64756 & 67281 & 77781 & 10500 & 15,6 & 13024 & 20,1 \\
\hline
\end{tabular}

Fonte: IBGE/PNADC. Elaboração: Lucas Carvalho (2020).

Enquanto o número de pessoas desocupadas no segundo trimestre de 2020 permanece relativamente estável, tanto em relação ao trimestre anterior quanto em relação ao mesmo trimestre do ano anterior $(2019 / 2)$, o número de pessoas ocupadas reduz, apresentando uma variação negativa de $-10,7 \%$ em relação a $2019 / 2$ para $-9,6 \%$ em $2020 / 1$. No segundo trimestre de 2020 , período da pandemia do Covid-19 e da recomendação de distanciamento social, a taxa de desocupação foi a segunda maior da série, e ficou em 13,3\%, com uma variação de $1,1 \%$ em relação ao primeiro trimestre de 2020 , e de $1,3 \%$ em relação ao mesmo trimestre do ano anterior. Só superada, portanto, pela taxa de desemprego do primeiro trimestre de 2017, que ficou em 13,7\% da PNADC (desde 2012). A comparação dos dados relativos às taxas de desocupação de 2019 e 2020 corrobora com o nosso argumento, de que a deterioração do mercado de trabalho antecede a pandemia.

Conforme sinalizam os pesquisadores do mercado de trabalho, não é suficiente olhar para as taxas de desocupação, por se tratar de um indicador calculado com base na porcentagem da força de trabalho que está desempregada. É necessário cotejar dados de desocupação com outras variáveis, como as taxas de subutilização da força de trabalho. Quando comparados os dados de 2019 com os dados do mercado de trabalho de 2020, observava-se o crescimento dos níveis de desocupação que saltam de $12 \%$ no segundo trimestre de 2019 para $13,3 \%$ no segundo trimestre de 2020 - contexto da pandemia. Quando observada a taxa combinada de desocupação e a força de trabalho potencial, observa-se 
o salto de $18,4 \%$ no segundo trimestre de 2019 para $24 \%$ no mesmo período de 2020 , evidenciado com a brusca redução na taxa de participação na força de trabalho e no nível de ocupação, com variação de $-5,7 \%$ e $-5,6 \%$, respectivamente, em relação ao primeiro trimestre de 2020 . A taxa composta de subutilização da força de trabalho ${ }^{10}$ demonstra que o número de pessoas trabalhando horas insuficientes também se altera: de 24,8\% no segundo semestre de 2019 para 29,1\% no mesmo período em 2020. ${ }^{11}$

Tabela 4 - Indicadores da força de trabalho - Brasil (trimestre)

\begin{tabular}{l|c|c|c|c|c}
\cline { 2 - 6 } & \multicolumn{2}{c|}{$\begin{array}{c}\text { Estimativas dos } \\
\text { trimestres }\end{array}$} & $\begin{array}{c}\text { Variação em relação } \\
\text { ao tri 2020/1 }\end{array}$ & $\begin{array}{c}\text { Variação em relação } \\
\text { ao tri 2019/2 }\end{array}$ \\
\cline { 2 - 6 } & $2019 / 2$ & $2020 / 1$ & $2020 / 2$ & Diferença & Diferença \\
\hline Taxa de desocupação & $12,0 \%$ & $12,2 \%$ & $13,3 \%$ & $1,1 \%$ & $1,3 \%$ \\
\hline Nível da ocupação & $54,6 \%$ & $53,5 \%$ & $47,9 \%$ & $-5,6 \%$ & $-6,7 \%$ \\
\hline $\begin{array}{l}\text { Taxa de participação } \\
\text { na força de trabalho }\end{array}$ & $62,1 \%$ & $61,0 \%$ & $55,3 \%$ & $-5,7 \%$ & $-6,8 \%$ \\
\hline $\begin{array}{l}\text { Taxa combinada de } \\
\text { desocupação e força } \\
\text { de trabalho potencial }\end{array}$ & $18,4 \%$ & $18,7 \%$ & $24,0 \%$ & $5,4 \%$ & $5,6 \%$ \\
\hline $\begin{array}{l}\text { Taxa composta } \\
\text { de subutilização } \\
\text { da força de trabalho** }\end{array}$ & $24,8 \%$ & $24,4 \%$ & $29,1 \%$ & $4,8 \%$ & $4,3 \%$ \\
\hline
\end{tabular}

Fonte: IBGE/PNADC. Elaboração: Lucas Carvalho (2020).

* Taxa combinada de desocupação e força de trabalho potencial: corresponde ao número de subocupados por insuficiência de horas + desocupados.

** Taxa composta de subutilização da força de trabalho corresponde aos subocupados por insuficiência de horas + desocupados + força de trabalho potencial (IBGE).

A Tabela 5 traz outros dados que permitem compreender o mercado de trabalho durante a pandemia. Observa-se a elevação no número de pessoas fora da força de trabalho em $+10.500 \mathrm{mi}$ em relação ao primeiro trimestre de 2020 , além de um incremento em $5.238 \mathrm{mi}$ de pessoas na força de trabalho potencial e 913 mil na população desalentada.

Como demonstram os dados, são visíveis os impactos da crise sanitária provocada pela Covid-19 no mercado de trabalho. Ocorre uma piora de um quadro que já vinha em franco processo de degradação ainda maior, ao menos desde a crise de 2015 , dadas as dinâmicas econômicas e políticas estabelecidas no país desde então.

Outro indicador importante refere-se ao tema da informalidade. Há um profícuo debate em torno do conceito da informalidade, sua insuficiência, ambiguidade, polissemia e dificuldades de medições precisas, dada a sua heterogendeidade e complexidade no presente (Véras de Oliveira, 2011) e das novas formas que se apresentam. A informalidade ${ }^{12}$ é uma das características estrutu- 
rantes do mercado de trabalho brasileiro, que vinha em decrescimento, como observado por Barbosa e Moura (2015), no período de 2002 a 2012, de 43,6\% para $32,5 \%$ em 2012 , com uma queda de 25,5 pontos percentuais. Esse quadro foi de piora em 2020, como se observa na Tabela 6 .

Tabela 5 - Indicadores de subutilização para população de 14 anos ou mais de idade

\begin{tabular}{l|c|c|c|c|c|c|c}
\cline { 2 - 8 } & \multicolumn{2}{c|}{$\begin{array}{c}\text { Estimativas dos } \\
\left.\text { trimestres (mi }{ }^{13}\right)\end{array}$} & \multicolumn{2}{c|}{$\begin{array}{c}\text { Variação em relação } \\
\text { ao tri 2020/1 }\end{array}$} & \multicolumn{2}{c}{$\begin{array}{c}\text { Variação em relação } \\
\text { ao tri 2019/2 }\end{array}$} \\
\cline { 2 - 8 } & 2019.2 & 2020.1 & 2020.2 & Diferença & VAR\% & Diferença & VAR\% \\
\hline $\begin{array}{l}\text { Subocupadas por } \\
\text { insuficiência de } \\
\text { horas trabalhadas }\end{array}$ & 7355 & 6467 & 5613 & -854 & $-13,2$ & -1742 & $-23,7$ \\
\hline $\begin{array}{l}\text { Desocupadas } \\
\text { Na força de trabalho } \\
\text { potencial }\end{array}$ & 12766 & 12850 & 12791 & -59 & $-0,5$ & 24 & 0,2 \\
\hline \begin{tabular}{l} 
Desalentadas \\
\hline
\end{tabular} & 4877 & 4770 & 5683 & 913 & 19,1 & 806 & 16,5 \\
\hline
\end{tabular}

Fonte: IBGE/PNADC. Elaboração: Lucas de Carvalho (2020).

Tabela 6 - Pessoas ocupadas por posição na ocupação, setor e categoria do emprego no trabalho principal (setor privado)

\begin{tabular}{l|c|c|c|c|c|c|c}
\cline { 2 - 8 } & \multicolumn{2}{c}{$\begin{array}{c}\text { Estimativas dos trimestres } \\
\text { (mil) }\end{array}$} & \multicolumn{2}{c|}{$\begin{array}{c}\text { Variação em } \\
\text { relação ao tri 2020/1 }\end{array}$} & \multicolumn{2}{c}{$\begin{array}{c}\text { Variação em } \\
\text { relação ao tri 2019/2 }\end{array}$} \\
\cline { 2 - 8 } & 2019.2 & 2020.1 & 2020.2 & Diferença & VAR\% & Diferença & VAR\% \\
\hline $\begin{array}{l}\text { Setor privado } \\
\text { (exclusive trabalhador } \\
\text { doméstico) }\end{array}$ & 44713 & 44119 & 38793 & -5327 & $-12,1 \%$ & -5920 & $-13,2 \%$ \\
\hline Com carteira & 33213 & 33096 & 30154 & -2942 & $-8,9 \%$ & -3059 & $-9,2 \%$ \\
\hline Sem carteira & 11500 & 11023 & 8639 & -2385 & $-21,6 \%$ & -2861 & $-24,9 \%$ \\
\hline Trabalhador doméstico & 6254 & 5971 & 4714 & -1257 & $-21,0 \%$ & -1540 & $-24,6 \%$ \\
\hline Com carteira & 1779 & 1640 & 1411 & -229 & $-13,9 \%$ & -368 & $-20,7 \%$ \\
\hline Sem carteira & 4476 & 4331 & 3303 & -1028 & $-23,7 \%$ & -1173 & $-26,2 \%$ \\
\hline
\end{tabular}

Fonte: IBGE/PNADC.

A variação percentual do número de pessoas ocupadas como empregados no setor privado (exclusive trabalhador doméstico) é de - $12,1 \%$ (pouco mais de cinco milhões de empregos perdidos) no trimestre 2020/2 em relação ao 2020/1. Considerando os trabalhadores com carteira assinada e os sem carteira assinada (informais), temos uma variação de $-8,9 \%$ para os primeiros, e de 
$-21,6 \%$ para os segundos; ou seja, o impacto causado pela pandemia foi mais do que dobrado para os informais, situação fortemente relacionada com a maior vulnerabilidde desses trabalhadores. Em relação aos trabalhadores domésticos, a variação percentual foi de $-21 \%$ no trimestre $2020 / 2$ em relação a $2020 / 1$. Para os trabalhadores domésticos com carteira assinada, a variação foi de $-13,9 \%$, e para os informais (sem carteira) foi de $-23,7 \%$. O impacto desigual também se observa para o caso das pessoas ocupadas como empregador ou conta própria.

Tabela 7 - Pessoas ocupadas por posição na ocupação, setor e categoria do emprego no trabalho principal (Empregadores, conta própria)

\begin{tabular}{l|c|c|c|c|c|c|c}
\cline { 2 - 8 } & \multicolumn{3}{c}{$\begin{array}{c}\text { Estimativas dos trimestres } \\
\text { (mil) }\end{array}$} & \multicolumn{2}{c|}{$\begin{array}{c}\text { Variação em } \\
\text { relação ao tri 2020.1 }\end{array}$} & \multicolumn{2}{c}{$\begin{array}{c}\text { Variação em } \\
\text { relação ao tri 2019.2 }\end{array}$} \\
\cline { 2 - 9 } & $2019 / 2$ & $2020 / 1$ & $2020 / 2$ & Diferença & VAR\% & Diferença & VAR\% \\
\hline Empregador & 4369 & 4385 & 3955 & -429 & $-9,8 \%$ & -414 & $-9,5 \%$ \\
\hline Com CNPJ & 3496 & 3584 & 3290 & -294 & $-8,2 \%$ & -206 & $-5,9 \%$ \\
\hline Sem CNPJ & 873 & 800 & 665 & -135 & $-16,9 \%$ & -208 & $-23,9 \%$ \\
\hline Conta própria & 24141 & 24159 & 21664 & -2495 & $-10,3 \%$ & -2477 & $-10,3 \%$ \\
\hline Com CNPJ & 4750 & 5444 & 5364 & -81 & $-1,5 \%$ & 614 & $12,9 \%$ \\
\hline Sem CNPJ & 9392 & 18714 & 16300 & -2414 & $-12,9 \%$ & -3092 & $-15,9 \%$ \\
\hline
\end{tabular}

Fonte: IBGE/PNADC. Elaboração: Lucas de Carvalho (2020).

O número de pessoas ocupadas como empregador e com CNPJ reduziu em $-8,2 \%$, enquanto que os sem CNPJ apresentam uma redução de $-16,9 \%$, como pode ser observado na Tabela 7 .

\section{O teletrabalho, ocupações e desigualdades regionais}

Outro dado significativo que revela a pesquisa PNAD-Covid- $19^{14}$ se deve aos indicadores sobre as diferentes ocupações e tipos de vínculos, que foram afetadas de formas distintas. Toda a classe trabalhadora dos mais diferentes setores da economia foi atingida, mas enquanto para uma grande parcela restou o desemprego, ou para os que se mantiveram ocupados medidas como a suspensão dos contratos de trabalho e acordos de redução de salários, por exemplo, para outros resultou em intensificação do trabalho e os desafios de terem que se adaptar rapidamente à modalidade do trabalho remoto, assumindo partes do custo do trabalho e jornadas para além das habituais.

Entre oito e nove milhões de trabalhadores, tanto do setor público quanto do privado, passaram a trabalhar na modalidade do teletrabalho (remoto/home office) em suas residências. A pesquisa PNAD-Covid-19 revelou que, em julho de 2020 , em torno de $10 \%$ da população ocupada estavam trabalhando remotamente, e os indicadores variavam semana a semana, com o menor patamar de 
8,184 milhões na terceira semana de julho e o maior, na primeira semana de junho com quase nove milhões de pessoas trabalhando remotamente, distribuídos desigualmente entre as diferentes regiões brasileiras. A maior fração foi concentrada no Sudeste, com $13 \%$ da população ocupada, e a menor fração (em torno de 4\%), na Região Norte do país.

De acordo com os dados de julho, os trabalhadores remotos com curso superior ou pós-graduação eram $31,1 \%$, seguidos, mas em patamar bem menor, de $5,9 \%$ pelos que possuem o médio completo ou superior incompleto. Apenas $1,5 \%$ dos trabalhadores nessa modalidade de trabalho se enquadra como sem instrução ou o fundamental incompleto. Essa desigualdade tem relação com o conteúdo do trabalho, visto que o trabalho remoto/bome office é predominantemente realizado de modo virtual, com o uso de computadores, webcams, plataformas digitais etc. Essa modalidade de trabalho, portanto, revela-se como um novo indicador de desigualdade econômica no país, além de o perfil dos trabalhadores ser altamente escolarizado e pelo tipo de ocupação. ${ }^{15}$

Quando analisamos os percentuais dos trabalhadores afastados em razão do distanciamento social pelo tipo de ocupação, predominam os empregados públicos sem carteira assinada e trabalhadores domésticos sem carteira. A partir de março de 2020 foram editadas Medidas Provisórias (MP 927) (MP 936), em razão do estado de calamidade pública, que possibilitaram o afastamento dos trabalhadores, conforme podemos observar no Quadro 1.

Quadro 1 - Afastados do trabalho: por ocupação

\begin{tabular}{l|c}
\hline Afastados do trabalho/ocupações & $\%$ \\
\hline Empregados do setor público sem carteira assinada & $17,4 \%$ \\
\hline Trabalhadores domésticos sem carteira assinada & $14,2 \%$ \\
\hline Militares e servidores estatutários & $13,9 \%$ \\
\hline Empregados do setor público com carteira assinada & $11 \%$ \\
\hline Trabalhadores domésticos com carteira assinada & $10 \%$ \\
\hline Empregados do setor privado sem carteira assinada & $8,8 \%$ \\
\hline Conta-própria & $7,5 \%$ \\
\hline Empregados do setor privado com carteira assinada & $6,6 \%$ \\
\hline Empregadores & $3,8 \%$ \\
\hline Trabalhadores familiares auxiliares & $2,3 \%$ \\
\hline
\end{tabular}

Fonte: PNAD-COVID-19/IBGE. Elaboração própria.

As condições em que se deram os afastamentos foram as mais variadas, $o$ tipo de vínculo de contratação determina a modalidade - com ou sem remuneração - e há situações ainda mais degradantes para os sem carteira, os mais 
vulneráveis e desprotegidos. Nesse sentido, a pandemia desmascara a condição dos trabalhadores que se encontram fora dos estatutos de proteção do trabalho, tais como os entregadores por aplicativos, que durante a pandemia realizaram diversas greves e manifestações. Nesse sentido, os entregadores, conforme analisa Galvão (2020, s.p.), estão descobrindo na realidade da crise sanitária "a falácia do discurso do empreendedorismo e revelando para os demais trabalhadores, mediante a visibilização de suas condições de trabalho, as ilusões que cercam um trabalho supostamente autônomo e flexível". A suposta liberdade professada pelos defensores dessas formas flexíveis de trabalho, segundo a autora, consiste apenas em "aumentar a velocidade de suas corridas e de permanecer mais tempo à disposição dos aplicativos para tentar melhorar seu ganho no final do dia".

As atividades econômicas mais atingidas e as desigualdades regionais

A pandemia também impacta de forma desigual as regiões do país, fato que traz à tona de forma visceral as desigualdades preexistentes. Na Tabela 8 encontram-se as pessoas ocupadas por grupamentos de atividades utilizados PNADC no Brasil para os anos 2019, primeiro trimestre, e de 2020, primeiro e segundo trimestres. Uma primeira observação relativa aos dados é a redução de $8.871 \mathrm{mi}$ no número de pessoas ocupadas em todos os setores quando comparados os dados do primeiro trimestre e segundo trimestre de 2020. Uma segunda observação é de que os setores foram afetados desigualmente, o que se deve também ao conteúdo da ocupação.

As ocupações relativas às atividades econômicas apresentando as maiores taxas de variação negativas são as de Alojamento e Alimentação, com a maior variação negativa de $-25,2 \%$ no número de pessoas ocupadas. Em seguida, vêm as dos Serviços Domésticos com variação de -21,1\%; Outros Serviços, com -16,7\%; seguida da Construção, com -16,6\%. Com variação negativa, mas em menor perda no número de ocupados, estão os demais grupamentos: Agricultura, Pecuária, Produção florestal, Pesca e aquicultura com variação negativa de $-3,5 \%$ em relação ao primeiro trimestre de 2020/1; Informação, Comunicação e Atividades financeiras, imobiliárias, profissionais e administrativas com variação de $-5,3 \%$.

Apenas o grupamento de atividade "Administração pública, defesa, seguridade, educação, saúde humana e serviços sociais" teve saldo positivo $(+1,6 \%)$, o que se deveu, em parte, a fato de o trabalho ser realizado na modalidade do teletrabalho. ${ }^{16}$

Quando o recorte dos dados sobre o mercado de trabalho se detém nas diferentes regiões do Brasil, identifica-se que a pandemia impacta todas as regiões, mas não de forma igual, como podemos observar na Tabela 9. As maiores variações percentuais positivas na taxa de desocupação foram no Centro-Oeste, no Sudeste e no Sul $(+1,9 \%,+1,5 \%$ e $+1,4 \%$, respectivamente $)$. Já em relação à variação do Nordeste, embora pouco significativa, possui a maior taxa de desocupação nesse trimestre, que fica em 16,1\%, seguido pelo Sudeste, com 13,9\%. 
Tabela 8 - Pessoas ocupadas por grupamentos de atividades - Brasil (trimestre)

\begin{tabular}{|c|c|c|c|c|c|c|c|}
\hline \multirow[t]{2}{*}{$\begin{array}{l}\text { Grupamento de } \\
\text { Atividade }\end{array}$} & \multicolumn{3}{|c|}{$\begin{array}{l}\text { Estimativas dos trimestres } \\
\text { (mil) }\end{array}$} & \multicolumn{2}{|c|}{\begin{tabular}{|c|} 
Variação em \\
relação ao tri 2020/1
\end{tabular}} & \multicolumn{2}{|c|}{$\begin{array}{l}\text { Variação em } \\
\text { relação ao tri 2019/2 }\end{array}$} \\
\hline & $2019 / 2$ & $2020 / 1$ & $2020 / 2$ & Diferença & VAR $\%$ & Diferença & VAR\% \\
\hline $\begin{array}{l}\text { Agricultura, pecuária, } \\
\text { produção florestal, } \\
\text { pesca e aquicultura }\end{array}$ & 8655 & 8266 & 7976 & -290 & $-3,5$ & -679 & $-7,8 \%$ \\
\hline Indústria Geral & 11986 & 11844 & 10727 & -1117 & $-9,4$ & -1259 & $-10,5 \%$ \\
\hline Construção & 6605 & 6380 & 5323 & -1057 & $-16,6$ & -1282 & $-19,4 \%$ \\
\hline $\begin{array}{l}\text { Comércio, reparação } \\
\text { de veículos } \\
\text { automotores } \\
\text { e motocicletas }\end{array}$ & 17531 & 17381 & 15244 & -2137 & $-12,3$ & -2287 & $-13,0 \%$ \\
\hline $\begin{array}{l}\text { Transporte, } \\
\text { armazenagem } \\
\text { e correio }\end{array}$ & 4862 & 4870 & 4341 & -529 & $-10,9$ & -521 & $-10,7 \%$ \\
\hline $\begin{array}{l}\text { Alojamento } \\
\text { e alimentação }\end{array}$ & 5417 & 5355 & 4006 & -1349 & $-25,2$ & -1411 & $-26,0 \%$ \\
\hline $\begin{array}{l}\text { Informação, } \\
\text { comunicação e } \\
\text { atividades financeiras, } \\
\text { imobiliárias, } \\
\text { profissionais } \\
\text { e administrativas }\end{array}$ & 10509 & 10625 & 10064 & -562 & $-5,3$ & -445 & $-4,2 \%$ \\
\hline $\begin{array}{l}\text { Administração pública, } \\
\text { defesa, seguridade, } \\
\text { educação, saúde } \\
\text { humana e serviços } \\
\text { sociais }\end{array}$ & 16451 & 16525 & 16789 & 264 & 1,6 & 338 & $2,1 \%$ \\
\hline Outros serviços & 4988 & 4940 & 4117 & -824 & $-16,7$ & -871 & $-17,5 \%$ \\
\hline Serviços domésticos & 6301 & 6016 & 4746 & -1270 & $-21,1$ & -1555 & $-24,7 \%$ \\
\hline Total & 93305 & 92202 & 83333 & -8871 & - & -9972 & - \\
\hline
\end{tabular}

Fonte: IBGE/PNADC. Elaboração: Lucas de Carvalho (2020).

As taxas de desocupação se distribuem desigualmente entre as diferentes regiões e estados da federação, com percentuais acima de 14\% (Amazonas, Maranhão, Bahia, Alagoas, Roraima, Rio Grande do Norte, São Paulo, Rio de Janeiro e Amapá); entre 13,3\% e 14,5\% (Pernambuco, Goiás e Distrito Federal); entre 11,6\% e 12,5\% (Pará, Espírito Santo, Minas Gerais, Sergipe, Ceará, Paraná e Paraíba); entre 10,4\% e 8,4\% (Tocantins, Mato Grosso, Mato Grosso do Sul, Rio Grande do Sul, Piauí, Rondônia e Santa Catarina) (PNAD-Covid-19/ IBGE, 2020).

Outro dado que expressa os efeitos da pandemia desigualmente se refere nos indicadores de cor, sexo e nível de escolaridade dos que deixaram de pro- 
curar emprego por conta da pandemia ou por falta de trabalho na localidade. O desemprego é maior entre pretos e pardos, bem como os ganhos salariais são menores, antes da pandemia, e se mantiveram em 2020. Enquanto a taxa de desocupação de brancos foi de 10,4\%, portanto abaixo da média nacional, para pretos foi de $17,8 \%$, e para pardos, de 15,4\%, portanto acima da média nacional. ${ }^{17}$ Considerando o grau de instrução, com até Ensino Médio incompleto, $23,1 \%$, enquanto com Médio incompleto e superior incompleto foi de $13,2 \%$. Com Superior completo e ou Pós-Graduação com o menor percentual $(5,7 \%)$. Em relação ao sexo, no segundo trimestre de 2020, a desocupação das mulheres foi de 14,9\%, e 12,0\% para os homens, e "as mulheres permanecem com o maior contingente entre as pessoas em idade de trabalhar $(53,0 \%)$ " (IBGE, $28 / 08 / 2020)$.

Tabela 9 - Pessoas ocupadas por Grande Região - Brasil (trimestre)

\begin{tabular}{|c|c|c|c|c|c|c|c|c|}
\hline \multirow{3}{*}{ Região } & \multirow{3}{*}{ Variável } & \multirow{2}{*}{\multicolumn{3}{|c|}{$\begin{array}{c}\text { Estimativas dos trimestres } \\
(\mathrm{mil})\end{array}$}} & \multirow{2}{*}{\multicolumn{2}{|c|}{$\begin{array}{c}\text { Variação em relação } \\
\text { ao tri 2020/1 }\end{array}$}} & \multirow{2}{*}{\multicolumn{2}{|c|}{$\begin{array}{l}\text { Variação em relação } \\
\text { ao tri } 2019 / 2\end{array}$}} \\
\hline & & & & & & & & \\
\hline & & $2019 / 2$ & $2020 / 1$ & $2020 / 2$ & Diferença & VAR\% & Diferença & VAR\% \\
\hline \multirow{3}{*}{ 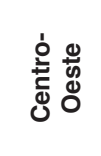 } & Taxa de desocupação & 10,3 & 10,6 & 12,5 & 1,9 & - & 2,3 & - \\
\hline & Ocupada & 7.829 & 7.711 & 7.085 & -625 & $-8,1$ & -743 & $-9,5$ \\
\hline & Desocupada & 896 & 912 & 1.015 & 103 & 11,2 & 119 & 13,2 \\
\hline \multirow{3}{*}{$\begin{array}{l}\frac{0}{8} \\
\frac{d}{0} \\
0\end{array}$} & Taxa de desocupação & 12,4 & 12,4 & 13,9 & 1,5 & - & 1,5 & - \\
\hline & Ocupada & 42.122 & 41.550 & 37.281 & -4.269 & $-10,3$ & -4.841 & $-11,5$ \\
\hline & Desocupada & 5.964 & 5.894 & 6.015 & 122 & 2,1 & 51 & 0,9 \\
\hline \multirow{3}{*}{ ले } & Taxa de desocupação & 8,0 & 7,5 & 8,9 & 1,4 & - & 0,9 & - \\
\hline & Ocupada & 14.768 & 14.698 & 13.930 & -768 & $-5,2$ & -837 & $-5,7$ \\
\hline & Desocupada & 1.281 & 1.196 & 1.357 & 161 & 13,4 & 75 & 5,9 \\
\hline \multirow{3}{*}{$\begin{array}{l}\frac{0}{ \pm} \\
\text { 은 }\end{array}$} & Taxa de desocupação & 11,8 & 11,9 & 11,8 & $-0,2$ & - & $-0,1$ & - \\
\hline & Ocupada & 7.338 & 7.383 & 6.841 & -542 & $-7,3$ & -497 & $-6,8$ \\
\hline & Desocupada & 985 & 999 & 913 & -87 & $-8,7$ & -73 & $-7,4$ \\
\hline \multirow{3}{*}{$\begin{array}{l}\stackrel{y}{y} \\
\frac{d}{0} \\
\text { 후 }\end{array}$} & Taxa de desocupação & 14,6 & 15,6 & 16,1 & 0,5 & - & 1,5 & - \\
\hline & Ocupada & 21.286 & 20.881 & 18.209 & -2.672 & $-12,8$ & -3.076 & $-14,5$ \\
\hline & & 3.639 & 3.849 & 3.491 & -358 & $-9,3$ & -148 & $-4,1$ \\
\hline
\end{tabular}

Fonte: IBGE/PNADC

\section{A pandemia também impacta o nível de renda}

As pessoas que continuaram ocupadas também foram impactadas com a queda da renda. A análise dos microdados da PNAD Covid-19 de maio revela "que os rendimentos médios habitualmente recebidos foram no valor de R $2.320,24$, enquanto os rendimentos médios efetivamente recebidos foram de R $\mathbf{1 . 8 9 8 , 8 6}$, ou seja, somente 82\% dos rendimentos habituais" (Sacchet de Carvalho, 2020, 
p.2). As maiores quedas têm relação com o tipo de vínculo de trabalho, as maiores perdas foram registradas para os trabalhadores por conta própria e informais.

Os trabalhadores por conta própria receberam efetivamente apenas $60 \%$ do que habitualmente recebiam, tendo seus rendimentos efetivos médios alcançando apenas R\$ $1.092,12$. Já os trabalhadores do setor privado sem carteira assinada receberam efetivamente $76 \%$ do habitual. Os empregadores também foram severamente atingidos, tendo recebido $69 \%$ do habitual, mas apresentando ainda um rendimento médio acima de R\$4.000. Entretanto, os trabalhadores formais foram consideravelmente menos atingidos. Trabalhadores do setor privado com carteira receberam em média 92\% do habitual, e os do setor público contratados pela Consolidação das Leis do Trabalho (CLT), 96\%. Entre militares e estatutários, a renda efetiva alcançou 98\% da renda habitual, e mesmo entre os trabalhadores informais do setor público a renda efetiva foi 91\% da habitual. (Sacchet de Carvalho, 2020, p.4)

Além dos vínculos, a queda de rendimento tem relação com a ocupação, o conteúdo da ocupação, caso dos trabalhadores prestadores de serviços pessoais, serviços domésticos, de alimentação, atividades imobiliárias, transporte de passageiros, construção civil, seguidos por serviços de alimentação. Entre os trabalhadores menos afetados estão os da Administração pública, da Indústria extrativa, de Utilidade pública, Educação, Sistema financeiro, Armazenamento, Correios e Serviços de entrega. ${ }^{18} \mathrm{~A}$ tragédia em termos salariais só não foi maior pela implementação do Auxilio Emergencial (AE) aprovado pelo Parlamento brasileiro como medida para assegurar uma renda mínima no período de crise econômica e do emprego em razão da pandemia. Em julho de 2020 esse programa atendeu 65 milhões de pessoas e cerca de 44,1\% dos domić́lios brasileiros. Vejamos os percentuais distribuídos entre as regiões do Brasil na Tabela 10.

Tabela 10 - Percentual de domicílios que recebem auxílio emergencial no total de domicílios (\%) - Brasil e Regiões

\begin{tabular}{l|c|c|c}
\hline & Maio & Junho & Julho \\
\hline Brasil & 38,7 & 43,0 & 44,1 \\
\hline Norte & 55,0 & 60,0 & 60,6 \\
\hline Nordeste & 54,8 & 58,9 & 59,6 \\
\hline Sudeste & 31,3 & 35,9 & 37,2 \\
\hline Sul & 26,0 & 29,7 & 30,9 \\
\hline Centro-Oeste & 36,7 & 41,4 & 41,9 \\
\hline
\end{tabular}

Fonte: IBGE/PNADC

Em termos de renda, como se pode observar, em razão desse auxílio, a média de rendimento proveniente do AE são maiores no Norte e no Nordeste, nos três meses analisados, ficando acima das demais regiões do país. 
Tabela 11 - Média do rendimento proveniente do auxílio emergencial recebido pelos domić́lios $(\mathrm{R} \$)$

\begin{tabular}{l|c|c|c}
\hline & Maio & Junho & Julho \\
\hline Brasil & 849 & 885 & 896 \\
\hline Norte & 938 & 961 & 973 \\
\hline Nordeste & 912 & 955 & 960 \\
\hline Sudeste & 791 & 829 & 847 \\
\hline Sul & 774 & 806 & 829 \\
\hline Centro-Oeste & 796 & 837 & 840 \\
\hline
\end{tabular}

Fonte: IBGE/PNADC

Em suma, os dados demonstram que a pandemia afetou a todos, embora seus efeitos tenham sido mais agudos e profundos em algumas regiões do país e para alguns grupos de trabalhadores dos mais diferentes setores econômicos e modalidades contratuais.

A deterioração do mercado de trabalho brasileiro tem relação com as novas configurações do trabalho na esteira do neoliberalismo dos anos 1980, 1990, com a reorganização das empresas e a produção de tipo enxuta e flexível e o conjunto de alterações na regulação dos direitos do trabalho que tornou o trabalho ainda mais flexível, desprotegido e inseguro. A pandemia da Covid-19, contudo, escancara as diversas desigualdades no trabalho, reguladas ainda que temporariamente pelas MP n.927 e n.936, visto que afetam a classe trabalhadora como um todo, mas de formas espefícificas em cada contexto regional, dependendo dos tipos de vínculo de trabalho, idade, escolarização, sexo, raça e tipo de atividade.

\section{Sindicalismo, pandemia e os desafios para os trabalhadores}

Os dados do IBGE sobre o sindicalismo revelam que após a contrarreforma trabalhista de 2017 as taxas de sindicalização caíram de forma mais acentuada. Com uma taxa de 16,1\% em 2012, em 2019 declinou $11,2 \%{ }^{19}$ Ou seja, em sete anos os sindicatos perderam pouco mais de 3.800 milhões de trabalhadores de suas fileiras. Essa redução tem relação com a recessão econômica, a queda dos postos de trabalho formais, como também com fatores como aposentadorias de servidores públicos motivadas pela Reforma da Previdência que vinha se desenhando desde o governo Temer e concretizada pelo governo Bolsonaro.

É nesse cenário crítico para o sindicalismo que os trabalhadores organizados buscam alternativas para proteção da vida e dos direitos dos trabalhadores durante a pandemia da Covid-19, tendo que agir defensivamente, com uma ação sindical na contramão das pautas governamentais e patronais que avançam no sentido da flexibilização direitos do trabalho. Nessa direção, conforme o Departamento Intersindical de Estatística e Estudos Socioeconômicos (Dieese), 
as negociações coletivas que tiveram como objeto a preservação da saúde e redução das dificuldades quanto ao emprego e a renda realizadas pelos sindicatos tiveram como temas: regras sanitárias nos locais de trabalho (com medidas que asseguram o distanciamento e higiene); licenças remuneradas e não remuneradas; trabalho remoto/home office; férias individuais ou coletivas; suspensão temporária do contrato de trabalho ou layoffe (possibilitada pela MP n.936/2020 que concedeu às empresas plenos poderes para negociar temas como suspensão de contratos de trabalho, salários e alterações na jornada).

Segundo o Dieese (2020), foram abrangidos por um conjunto das negociações com itens referentes ao cenário da pandemia em torno de 4,4l milhões de trabalhadores em todo o país. Foram registrados 7.398 instrumentos coletivos no Mediador - um módulo do Sistema Integrado de Relações do Trabalho da Secretaria do Trabalho de registro de convenções e acordos coletivos via internet -, no período de março a junho, portanto durante a pandemia, quando o tema passou a ser objeto de negociação coletiva no Brasil. Os principais temas negociados foram: afastamento de trabalhadores no grupo de risco, teletrabalho (sempre que possível), fornecimento de Equipamentos de Proteção Individual (EPI), higienização, testes rápidos para detecção do Covid-19, hospedagem para evitar contágio de familiares, adequação da jornada para evitar aglomerações no transporte e local de refeição, adequação dos processos de trabalho, condições para realização do trabalho de forma remota (tais como fornecimento de equipamentos, ajuda de custo para pagamento de despesas como internet, telefone e energia elétrica), e registro de jornada de trabalho (Dieese, 2020). Segundo o balanço do Dieese, em termos de remuneração, no primeiro semestre de 2020 houve queda nas cláusulas referentes a reajustes salariais de $28 \%$, se comparados a 2019. Portanto, nesse contexto de recessão econômica e de contração da sindicalização, dada a redução do trabalho formal no país, mas também em razão do viés antissindical do governo, os sindicatos estão buscando construir alternativas para assegurar as condições básicas de trabalho no cenário da pandemia e posterior a ela.

\section{Considerações finais}

Tratar dos impactos da crise sanitária trazida pelo vírus da Covid-19 nos remete às rupturas que vêm ocorrendo em várias direções provocadas pelas crises capitalistas dos anos 1970 que levaram à transição de um sistema de acumulação, então cunhado de fordista, dos contratos por tempo indeterminado, dos sistemas de proteção do trabalho, para um sistema de acumulação flexível, em que passam a prevalecer as mais diferentes formas de contratos de trabalho flexíveis, de trabalhadores por tempo parcial, temporários, terceirizados, entre outras. O trabalho profundamente reconfigurado assume feições e formatos tanto quanto à sua realização quanto às suas formas de contratação aproximando-se da característica do capitalismo do século XVIII e XIX, desprotegido, incerto, completamente mercantilizado, desregulado. 
No Brasil, a contrarreforma laboral de 2017 promoveu concomitantemente dois efeitos, a desconstrução de direitos e a fragilização das instituições públicas e dos sindicatos, como analisa Krein et al. (2018). Ampliou as modalidades de contratos flexíveis e, consequentemente, precárias, criou ou renomeou formas já existentes, caso do contrato intermitente, a terceirização irrestrita, a pessoa jurídica, entre outras. Além de promover o enfraquecimento das instituições públicas do trabalho, segundo Krein et al. (2018), favoreceu a regulação privada do trabalho a "livre" negociação entre empregador e empregado de forma individual, reestabelecendo o face a face predominante na fase do capitalismo liberal dos séculos XVIII e XIX na Europa.

A redução do poder dos sindicatos foi uma das linhas mestras orientadoras da contrarreforma conduzida pelos agentes do mercado e aprovadas pelas instâncias políticas conservadoras e adotadas de forma preponderante no país.

Portanto, a crise de 2020 impulsionada pela Covid-19 colocará um ingrediente mortífero a mais para a classe trabalhadora, já bastante frágil pela crise econômica que se abateu sobre o país desde 2015, que ampliou taxas de desemprego e avanço da informalização do trabalho.

Os desafios para o cenário pós-pandemia consistem em produzir crescimento econômico com distribuição de renda, mas para isso urge fortalecer o papel do Estado para o fomento de geração de emprego, assim como os sindicatos, atores centrais na luta para elevação das melhorias das condições salariais e de trabalho, bem como o fortalecimento da regulação pública do trabalho em detrimento da regulação privada, da adoção de políticas de criação de emprego e política de renda universal. Para isso, terá que se voltar atrás, para avançar na construção de uma nova ordem que torne de vez o neoliberalismo e seus rudimentos uma mera sombra do passado.

O ideário neoliberal que retornou a nortear o Brasil, ao menos desde a ascensão de Michel Temer, encontra-se profundamente abalado. Em primeiro lugar, porque as promessas de melhoria na dinâmica econômica do país não foram realizadas, tampouco a criação de empregos e ampliação da formalização. A desigualdade avançou e o país retrocedeu em diversos aspectos. Mas o fato novo provocado pela pandemia consistiu em expor empiricamente as incapacidades do neoliberalismo de fazer frente à crise econômica resultante da pandemia. A inépcia do mercado de agir e reagir sem o aporte do Estado se escancara mais uma vez. Contudo, não foi a primeira crise que colocou o neoliberalismo em xeque e talvez não será a última. Mas se revela como mais um capítulo que joga por terra seus fundamentos. Governos neoliberais em diversas partes do mundo estão sendo obrigados a agir para contrarrestar os fundamentos neoliberais.

No Brasil, a Emenda Constitucional n.95 submeteu o país a uma condição sem saída, na medida em que não apenas constrange, mas impede o Estado da adoção de políticas anticlícas. Sem a possibilidade de o país construir alterna- 
tivas para dinamizar a economia, e criar políticas de emprego e renda, antevê-se o caos social.

A pandemia desnudou o drama da classe trabalhadora destituída dos direitos do trabalho e dos chamados "empreendedores", situação dos entregadores por aplicativos que, no Brasil, só no contexto da pandemia, realizaram diversas greves contra a desproteção ante a ameaça de contração do vírus da Covid-19 e os baixos rendimentos.

As "velhas" formas de trabalho desprotegido e inseguro do ponto de vista do direito se globalizaram. A precariedade característica dessas modalidades se entendeu também para as "novas" ocupações, para os qualificados, para aquelas ocupações mediadas pelas tecnologias da informação, cada vez mais submetidos a formas flexíveis de trabalho. É a precariedade no e do trabalho que se universaliza. Embora essas condições não se devam à pandemia, mas ao movimento geral de reestruturação do mundo do trabalho desde as últimas décadas do século XX, a Covid-19 desnuda a fragilidade dessas formas de trabalho totalmente mercantilizadas. Nesse sentido, fortalecer a regulação pública do trabalho é uma condição central para reduzir as desigualdades e a precariedade do trabalho. A retomada dos investimentos públicos para obras de infraestrutura, a melhoria dos serviços públicos, investimentos em ciência, educação, saúde, por exemplo, implica necessariamente cancelamento do limite de gastos imposto ao país.

A análise de todas as medidas do governo Bolsonaro e a política do ministro Paulo Guedes corroboram o fato de que as medidas adotadas foram no sentido de explorar ainda mais a mão de obra, ao constranger salários, flexibilizar regras e direitos e atender especificamente à agenda do mercado. Urge construir outra política que vá na contramão da austeridade e das ações antitrabalhadores. As saídas para o enfrentamento dos efeitos causados pela pandemia da Covid-19 estão na taxação de grandes fortunas, taxação do rentismo e na adoção de uma política de renda universal. Evidentemente que isso implica enterrar o neoliberalismo e as políticas de austeridade, o que exige compromisso com o social, com os valores da democracia.

\section{Notas}

1 Agradeço a Ana Paula D’Ávila a leitura atenta do texto e sugestões, e ao Lucas Carvalho, as tabelas e contribuição na discussão dos dados.

2 Nota do IBGE: a partir do quarto trimestre de 2015 houve mudança de conceito na subutilização da força de trabalho por insuficiência de horas trabalhadas. Anteriormente, considerava-se no cálculo do indicador as horas efetivamente trabalhadas e, a partir do referido trimestre, as habitualmente trabalhadas. Houve ainda mudança na forma de captação do quesito de horas trabalhadas.

$3 \mathrm{O}$ governo brasileiro realizou nessa década uma minirreforma com as medidas de flexibilização do trabalho realizadas no governo de Fernando Henrique Cardoso. Essa reforma estabeleceu os contratos por tempo determinado, eliminou mecanismos de 
inibição de demissão imotivada, permitiu a formação de cooperativas de trabalhadores sem vínculo empregatício, estabeleceu o trabalho de tempo parcial, temporário. Flexibilizou jornadas e remuneração, entre outras medidas. Sobre isso, ver Krein (2001).

4 Ver o balanço na primeira publicação da Rede de Estudos e Monitoramento Interdisciplinar da Reforma Trabalhista (Remir). Disponível em: <https://www.cesit.net.br/ reforma-trabalhista-no-brasil-promessas-e-realidade/ $>$.

5 Ver a obra publicada pela Remir, organizada por Krein, Véras de Oliveira e Filgueiras (2019).

6 Sobre essa MP, ver a publicação organizada por Passos, Melo e Nicoladeli (2019).

7 Ver em Agência Senado. Disponível em: <https://wwwl2.senado.leg.br/noticias/ materias $/ 2019 / 08 / 21 /$ aprovada-mp-da-liberdade-economica-sem-regras-de-trabalho-aos-domingos $>$.

8 Ver o artigo completo de Teixeira e Borsari (2020).

9 Notas explicativas sobre os conceitos utlizados (Cf. IBGE): Nota 1. Desocupação: pessoas que não trabalharam na semana de referência e que buscaram emprego. Nota 2. Ocupação: são classificadas como ocupadas as pessoas que trabalharam pelo menos uma hora em atividade remunerada (dinheiro ou mercadorias) na semana de referência da pesquisa. Nota 3. Na Força de Trabalho: pessoas na força de trabalho na semana de referência compreendem as pessoas ocupadas e as pessoas desocupadas nessa semana. Nota 4. Fora da Força de Trabalho: São classificadas como fora da força de trabalho na semana de referência as pessoas que não estavam ocupadas nem desocupadas nessa semana. Nota 5. Taxa de desocupação: É o percentual de pessoas desocupadas, na semana de referência, em relação às pessoas na força de trabalho nessa semana: [pessoas desocupadas / pessoas na força de trabalho] x 100. Nota 6. Nível de ocupação: É o percentual de pessoas desocupadas, na semana de referência, em relação às pessoas em idade de trabalhar: [pessoas desocupadas / pessoas em idade de trabalhar] x 100. Nota 7. Taxa de participação na força de trabalho: É o percentual de pessoas na força de trabalho, na semana de referência, em relação às pessoas em idade de trabalhar: [pessoas na força de trabalho / pessoas em idade de trabalhar] x 100 (IBGE-PNAD).

$10 \mathrm{O}$ IBGE esclarece que as pessoas que trabalham horas insuficientes atendem quatro requisitos básicos: " 1 . tinham 14 anos ou mais de idade; 2 . trabalhavam habitualmente menos de 40 horas no seu único trabalho ou no conjunto de todos os seus trabalhos; 3 . gostariam de trabalhar mais horas que as habitualmente trabalhadas; e 4. estavam disponíveis para trabalhar mais horas no período de 30 dias, contados a partir do primeiro dia da semana de referência". A insuficiência de jornada de trabalho. Insuficiência de horas trabalhadas, segundo nota técnica do IPEA de Machado e Machado (2006) está associada à insuficiência de renda no sentido de rendimento abaixo da média.

11 Em nota explicativa, o IBGE destaca que a parir do " $4^{\circ}$ trimestre de 2015 houve mudança de conceito na subutilização da força de trabalho por insuficiência de horas trabalhadas. Anteriormente, considerava-se no cálculo do indicador as horas efetivamente trabalhadas e, a partir do referido trimestre, as habitualmente trabalhadas. Houve ainda mudança na forma de captação do quesito de horas trabalhadas. Por conta disto, não são realizadas comparações (trimestrais e/ou anuais) entre trimestres que não compartilham o mesmo conceito/forma de captação".

12 Dada a complexidade da informalidade, utilizamos a referência dada pelo IBGE, se- 
gundo o qual são considerados informais os empregados que não possuem vínculos formalizados com a empresa contratante, além de empregadores e trabalhadores por conta própria, sem CNPJ e contribuição para a Previdência Social do país.

13 Sempre que no título da variável estiver "mil”, multiplicam-se os valores por 1.000.

14 A PNAD Covid-19 realizada pelo IBGE começou a ser aplicada em maio de 2020, por telefone, tem dois objetivos básicos: o de estimar o número de pessoas com sintomas referidos associados a Covid-19 e os impactos do mercado de trabalho brasileiro.

15 Folha de S.Paulo. "Home office é novo indicador de desigualdade econômica no Brasil" 30.8.2020. Disponível em: <https://wwwl.folha.uol.com.br/mercado/2020/08/ home-office-e-novo-indicador-de-desigualdade-economica-no-brasil.shtml> Acesso em: 31 ago. 2020.

16 Sobre as condições de trabalho remoto durante a pandemia, ver o Relatório de Pesquisa "Trabalho remoto/home office no contexto da pandemia Covid-19", que contou com a participação de 906 trabalhadores entrevistados, ver site da Remir. Disponível em: <http://www.eco.unicamp.br/remir/index.php/remir-2>.

17 Disponível em: <https://agenciadenoticias.ibge.gov.br/agencia-noticias/2012-agen-cia-de-noticias/noticias/28700-desemprego-avanca-em-11-estados-no-2-trimestre-amapa-e-para-tem-queda>. Acesso em: 7 set. 2020.

18 Disponível em: <https://www.ipea.gov.br/portal/images/stories/PDFs/conjuntura/200702_cc_48_mercado_de_trabalho.pdf>.

19 Ver PNAD Contínua anual: Características Adicionais do Mercado de Trabalho, publicado em 26 de agosto de 2020.

20 O layoff, como esclarece o DIEESE (2020, p.3), tem "base no Artigo 476-A da CLT, que dispõe sobre a possibilidade de suspensão do contrato de trabalho por dois a cinco meses, período no qual os empregados participarão de cursos de qualificação profissional oferecidos pelo empregador e poderão receber ajuda compensatória mensal, sem natureza salarial, com valor definido em convenção ou acordo coletivo".

\section{Referências}

ARAÚJO, A.; VÉRAS DE OLIVEIRA, R. O sindicalismo na era Lula: entre paradoxos e novas perspectivas. In: VÉRAS DE OLIVEIRA, R.; BRIDI, M. A.; FERRAZ, M. (Org.) O sindicalismo na Era Lula: paradoxos, perspectivas e olhares. Belo Horizonte: Fino Trato, 2014.

BRESSER-PEREIRA, L. C.; THEUER, D. Um Estado novo-desenvolvimentista na América Latina? Economia e Sociedade, Campinas, v.21, número especial, p.811-29, 2012.

BARBOSA FILHO, F. de H.; MOURA, R. L. de. Evolução recente da informalidade do emprego no Brasil: uma análise segundo as características da Oferta de trabalho e o setor. Pesquisa e Planejamento Econômico, Brasília, v.45, n.1, 2015.

BRIDI, M. A. Reforma trabalhista no Brasil, austeridade e retrocesso social. In: PACHECO, C. et al. (Org.) A América Latina hoje: rupturas e continuidades. Curitiba: Editora Instituto Memória, 2020.

CARVAlHO, L. Análise de Conjuntura Mercado de Trabalho - pré e durante pandemia. UFPR: GETS, 2020 (mimeo). 
DIEESE. Anuário do Sistema Público de Emprego, Trabalbo e Renda 2015: mercado de trabalho: livro 1./ Departamento.

DIEESE. Acordos negociados pelas entidades sindicais para enfrentar a pandemia do coronavírus - Covid 19. Estudos e Pesquisas. Disponível em: <https://www.dieese.org. br/estudosepesquisas/2020/estPesq92AcordosCovidAtualizacao.pdf>. Acesso em: 2 set. 2020.

DIEESE. De olho nas negociações. Boletim 1, Agosto de 2020. Disponível em: <Ihttps://www.dieese.org.br/boletimnegociacao/2020/boletimnegociacao01.pdf>. Acesso em: 2 set. 2020 .

FILGUEIRAS, V. As promessas da Reforma Trabalhista: combate ao desemprego e redução da informalidade. In: KREIN, J. D.; VÉRAS DE OLIVEIRA, R.; FILGUEIRAS, V. (Org.) Reforma Trabalhista no Brasil: promessas e realidade. Campinas: Editora Curt Nimeundajú, 2019.

GALVÃO, A. Reforma Trabalhista: efeitos e perspectivas para os sindicatos. In: KREIN, J. D.; VÉRAS DE OLIVEIRA, R.; FILGUEIRAS, V. (Org.) Reforma Trabalhista no Brasil: promessas e realidade. Campinas: Editora Curt Nimeundajú, 2019.

A greve, o breque, o trampo: a luta do entregadores é a luta dos trabalhadores. Esquerda Diário, 3 de julho, 2020. Disponível em: <https://www.esquerdadiario.com. br/A-greve-o-breque-o-trampo-a-luta-do-entregadores-e-a-luta-dos-trabalhadores $>$. Acesso em: 4 set. 2020.

GOMES, M. C. As negociações coletivas na construção civil leve do Paraná: contexto dos governos Lula e Dilma (2001-2014). Curitiba, 2017. Tese (Doutorado) - Universidade Federal do Paraná.

IBGE. Pesquisa Nacional por Amostra de Domicilios Contínua - Notas Metodológicas. Rio de Janeiro: IBGE, 2014.

IBGE. Pesquisa Nacional por Amostra de Domicílios Contínua. Diversos anos. Disponível em: <https://www.ibge.gov.br/estatisticas/sociais/trabalho.html>.

IBGE. Pesquisa Nacional por Amostra de Domicílios - Covid-19. Disponível em: <https://covid19.ibge.gov.br/pnad-covid/trabalho.php>.

KREIN, J. D. O desmonte dos direitos, as novas configurações do trabalho e o esvaziamento da ação coletiva. Tempo Social, Revista de sociologia da USP, v.30, n.1. 2018. Disponível em: <https://www.scielo.br/pdf/ts/v30nl/1809-4554-ts-30-01-0077. pdf>.

KREIN, J. D.; ABÍLIO, L.; FREITAS, P.; BORSARI, P.; CRUZ, R. Flexibilização das relações de trabalho: insegurança para os trabalhadores. In: KREIN, J. D; ANSELMO, D. M. G. (Orgs). Dimensões criticas da reforma trabalhista no Brasil. Campinas: Curt Nimuendajú, 2018.

KREIN, J. D.; VÉRAS DE OLIVEIRA, R. Os impactos da Reforma nas condições de trabalho. In: KREIN, J. D; VÉRAS DE OLIVEIRA, R.; FILGUEIRAS. V. Reforma trabalhista no Brasil: promessas e realidade. Campinas: Curt Nimuendajú, 2019.

LÚCIO, C. G. O novo mundo do trabalho é flexível, precário e inseguro. Carta Social e do Trabalho, Campinas, n.38, p.1-11, jul./dez. 2018.

MACHADO, D. C.; MACHADO, A. F. Nota técnica: Um aspecto da subocupação 
por insuficiência de horas trabalhadas: a análise do desejo de trabalhar horas adicionais. 2006. Disponível em: <http://repositorio.ipea.gov.br/bitstream/11058/4106/1/ bmt33_02_notatecnica02.pdf>. Acesso em: 1 set. 2020.

PASSOS, A.; MELO, R. S. de; NICOLADELI, S. L. Financiamento Sindical no Brasil: reflexões sócio-jurídicas e o curioso caso da MP 873/2019. Curitiba: RTM, 2019.

POCHMANN, M. Políticas sociais e padrão de mudanças no Brasil durante o governo Lula. Revista SER Social, Brasília, v.13, n.28, p.12-40, 2011.

PORTELLA, G. O direito do trabalho do não-assalariado: nova informalidade e as zonas cinzentas do assalariamento no Brasil. Curitiba, 2020. Dissertação (Mestrado) - Universidade Federal do Paraná.

SACCHET DE CARVALHO, S. Os efeitos da pandemia sobre os rendimentos do trabalho e o impacto do auxílio emergencial: o que dizem os microdados da PNAD covid-19. Carta de Conjuntura, v.48, $3^{\circ}$ trimestre de 2020, IPEA, 2020.

TEIXEIRA, M.; BORSARI, P. Mercado de trabalho no contexto da pandemia: a situação do Brasil até abril de 2020. Campinas: Unicamp; Cesit, 2020. Disponível em: <https://www.cesit.net.br/mercado-de-trabalho-no-contexto-da-pandemia-a-situacao-do-brasil-ate-abril-de-2020/>. Acesso em: 8 set. 2020.

VÉRAS DE OLIVEIRA, R. Para discutir os termos da nova informalidade: sobre sua validade enquanto categoria de análise na era da flexibilização. In: VÉRAS DE OLIVEIRA, R. et al. (Org.) Marchas e contramarchas da informalidade do trabalho: das origens às novas abordagens. João Pessoa: Ed. Universitária da UFPB, 2011.

RESUMO - A partir da análise de dados do IBGE sobre o mercado de trabalho no período pré e durante pandemia, além de literatura pertinente, este artigo contempla três dimensões: (i) traça um breve panorama sobre o contexto de crise econômica e do emprego e das mudanças que redundaram na reforma laboral de 2017 e os indicadores do mercado de trabalho no período que antecede a crise sanitária; (ii) os indicadores do mercado de trabalho no contexto da pandemia, que sinalizam os impactos sobre o trabalho; (iii) os desafios impostos ao sindicalismo decorrentes da intensificação da agenda neoliberal dos últimos quatro anos. Demonstra que a crise sanitária causada pelo SarsCoV-2 potencializou a fragilidade do mercado de trabalho que vinha em franco processo de deterioração nos últimos quatro anos no Brasil. Atingiu, de forma contundente e de diversas maneiras toda a classe trabalhadora dos diversos setores econômicos e de forma desigual nas diferentes regiões do Brasil.

PALAVRAS-CHAVE: Covid-19, Mercado de trabalho, Reforma laboral.

ABSTRACT - Based on the analysis of IBGE data on the labor market before and during the pandemic, as well as on relevant literature, this article contemplates three dimensions: (i) a brief overview of the context of the economic and employment crisis, of the changes that resulted in the 2017 labor reform and of labor market indicators in the period prior to the health crisis; (ii) labor market indicators in the context of the pandemic, which signal impacts on labor; (iii) the challenges imposed on labor unions resulting from the intensification of the neoliberal agenda of the last four years. The article shows that the health crisis caused by Sars-CoV-2 has increased the fragility of the 
labor market, which had already been in a process of deterioration in the last four years in Brazil. It hit the working class of various economic sectors in striking and diverse manners, and unevenly in the different regions of Brazil.

KEYWORDS: Covid-19, Labor market, Labor reform.

Maria Aparecida Bridi é socióloga, professora do departamento de Sociologia (Deciso) e do Programa de Pós-Graduação em Sociologia da Universidade Federal do Paraná; vice-presidente da Associação Brasileira de Estudos do Trabalho (Abet) e membro da coordenação nacional da Rede de Estudos e Monitoramento da Reforma Trabalhista (Remir). É coeditora da Revista da Abet. @ - macbridi@gmail.com / https://orcid.org/0000.0001-8004.1360.

Recebido em 10.9.2020 e aceito em 28.9.2020.

I Programa de Pós-Graduação em Sociologia, Universidade Federal do Paraná, Curitiba, Paraná, Brasil. 
